10.21611/qirt.2016.130

\title{
Changes in skin temperature during interval type of physical exercise measured by infrared thermography
}

\author{
by V. Svaic*, A. Bolaric ${ }^{* *}$, D. Zupanic ${ }^{* *}$ and B. Jurinjak**
}

*SkiBoo Sports Academy, Zagreb, Croatia, vjeran.svaic@skiboo.hr

** Mag.Ing.Mech. student at University of Zagreb, Faculty of Mechanical Engineering and Naval Architecture, Zagreb, Croatia

\begin{abstract}
The main purpose of this investigation was to analyze the effect of interval type of physical exercise on skin temperature changes of the knees. Subject were instructed to ride a stationary bicycle with 90 second periods of work and 30 second periods of rest, in a low to moderate physical strain. Statistically significant differences were found between mean activity and recovery skin temperatures, and mean rest and recovery skin temperatures. Interval fall in skin temperature can be seen during short periods of work, which is followed by a rise in skin temperature when subjects are given short time to rest.
\end{abstract}

\section{Introduction}

In the field of pathology diagnostic, applied to sports activity, the application of infrared thermography (IRT) has a long history, mainly musculoskeletal trauma, pathologic processes such as pain in the lumbosacral region, intervertebral disc prolapse, spinal cord lesion, traumatic lesions, fractures, cardiovascular etc. Assessing pain by infrared thermography is a diagnostic method providing information on the normal and abnormal sensory and nervous systems, trauma, or inflammation locally and globally. However, interest in IRT today is growing because of improved devices and methods of calculation. The special characteristic of IRT studies is that we can get additional information about the skin thermal aspect and about the complex thermoregulatory process. IRT gives a possibility to evaluate the effect of the sporting activity and to detect possible trauma or dysfunctions, which cannot be shown by present conventional methods. It can measure skin temperature $\left(T_{s k}\right)$ over inflamed joints. This developing technology is used to detect thermal abnormalities characterized by a temperature increase or decrease found at the skin surface. The technique involves the detection of infrared radiation that can be directly correlated with the temperature distribution of a body region. It is well known that physical activity induces a complex thermoregulation process where part of heat is given off by the skin of athlete. As not all the heat produced can be entirely given off, there follows a muscular heating resulting in an increase in the cutaneous temperature. Infrared thermography shows physiological changes rather than anatomical changes and could be a new diagnostic tool.

This still young in application and developing technology can be utilized to detect, locate and monitor thermal changes or abnormalities characterized by an increase or decrease in skin temperature and consequently it is a valuable tool in sport, sports medicine and physical therapy. It is regarded as a basic physiological measure reporting temperature (skin, muscle and/or core) following the application or exposure to any therapeutic thermal agent and widely used in assessing of the effects of heat stress, muscle soreness recovery, aerobic performance in hot and humid conditions, electromyography activity, functional performance or rehabilitation [1]. Skin temperature is determined by multiple factors such as a combination of conduction of the heat from the working musculature, 


\subsection{1/qirt.2016.130}

perfusion of the blood and heat exchange between human body and the environment. Physical activity increases central body temperature due to the higher production of energy in involved musculature during physical work [2]. Physical activity influences the initial fall in skin temperature over the working musculature after which a continuous rise in skin temperature occurs. This initial fall in skin temperature is associated with a higher demand of blood flow in the working musculature leading to the skin reflex vasoconstriction response of the blood vessels [3]. Sampedro, Piñonosa and Fernandez [4] investigated thermographic behavior of a professional basketball player and found difference of more than $0.5^{\circ} \mathrm{C}$ between symmetrical areas of the body. Whereas Novotny et al. [5] did not find any significant differences between symmetrical areas of the body during different types of swimming, and found a relative decrease after swimming in temperature of the muscles pectoralis, rhombic and lower trapezius, erector spinae lumbalis and latissimus dorsi, together with the increase in the temperature of triceps brachii. Piñonosa et al. [6] applied IRT to establish thermal difference between the beginning and the end of the anterior cruciate ligament rehabilitation process after surgery. Their results showed significant temperature increases in the posterior thigh area between the first and the last week of the rehabilitation process probably due to a compensatory mechanism. The aim of this paper is to contribute to the knowledge in the area of temperature changes of the knee joints during interval type of physical activity on a stationary bicycle.

\section{Methodology}

Twenty three male non-athletic student volunteers were involved in this investigation with the mean age 19 years. The experiment took part at the Thermo Laboratory of Faculty of Mechanical Engineering and Naval Architecture of University of Zagreb. The participants were all healthy and had signed an informed written consent. During the experiment the subjects were dressed in shorts and T-shirt. Stationary bicycle was placed in the climatic chamber where the experiment was conducted and students participated in the experiment one at a time. Mean temperature in the chamber was $24.8( \pm 0.6){ }^{\circ} \mathrm{C}$ and relative humidity $20.1( \pm 2.3) \%$. After acquiring basic information of participants, the experiment started with the ten minute acclimatization phase in a sitting position. General information of the subjects and climatic conditions can be seen in table 1.

Table 1. Descriptive statistics

\begin{tabular}{|l|c|c|c|c|c|c|}
\hline & $N$ & Range & Minimum & Maximum & Mean & $S D$ \\
\hline Age (years) & 23 & 3.0 & 18.0 & 21.0 & 19.3 & 0.7 \\
\hline Height $(\mathrm{cm})$ & 23 & 30.0 & 170.0 & 200.0 & 183.9 & 7.8 \\
\hline Weight $(\mathrm{kg})$ & 23 & 73.3 & 59.9 & 133.2 & 81.8 & 14.5 \\
\hline BMI & 23 & 20.6 & 17.5 & 38.1 & 24.2 & 3.9 \\
\hline Ambient temperature ( $\mathrm{C})$ & 23 & 2.3 & 23.7 & 25.8 & 24.8 & 0.6 \\
\hline Relative humidity (\%) & 23 & 10.1 & 17.4 & 27.5 & 20.1 & 2.3 \\
\hline
\end{tabular}

${ }^{*} \mathrm{BMI}$ - body mass index, SD - standard deviation

The main purpose of this investigation was to analyze the effect of interval type of physical exercise on skin temperature of the knees. The experiment lasted for a total of 30 minutes with ten minute rest period (RES), ten minute activity period (ACT) and 10 minute recovery period (REC). During the ten minute activity period subject were instructed to ride a stationary bicycle with 90 second periods of work and 30 second periods of rest, in a low to moderate physical strain with the heart rate $(\mathrm{HR})$ of $65( \pm 5) \%$ of the predicted maximal heart rate. Polar heart beat monitor RS300X was used to measure heart rate. Thermograms of the anterior side of the knees were taken 


\subsection{1/qirt.2016.130}

according to the Glamorgan protocol, as a standardized methodological procedure, in order to get the most accurate results [7]. The recording was made after every minute of the investigation. Three independent examiners provided results after a quantitative analysis of the thermograms and the average temperature of the three examiners at every point (minute) of the recording was then used as a final result, with a total of thirty thermograms. A high objectivity was calculated among the examiners with Cronbach a 0.98 during all three periods. Flir SC2000 infrared thermocamera was used for recoding thermograms and ThermaCAM Researcher 2002 Application (Flir Systems AB, Sweden) was used for the quantitative analysis.

\section{Results and discussion}

During RES period a steady temperature is seen throughout total of ten minutes recording with a mean temperature of both knees at $29.5^{\circ} \mathrm{C}$. After the ten minute period of rest subjects began with the physical activity. A fall in skin temperature $\left(T_{\mathrm{sk}}\right)$ can be seen during ACT short periods of work (90 seconds), which is followed by a rise in $T_{\text {sk }}$ when given a short time to rest (30 seconds). It is visually clear from the graph (Fig.1.) that every time subjects started pedaling this fall in $T_{\text {sk }}$ occurred. Activity period again lasted for the total of ten minutes.

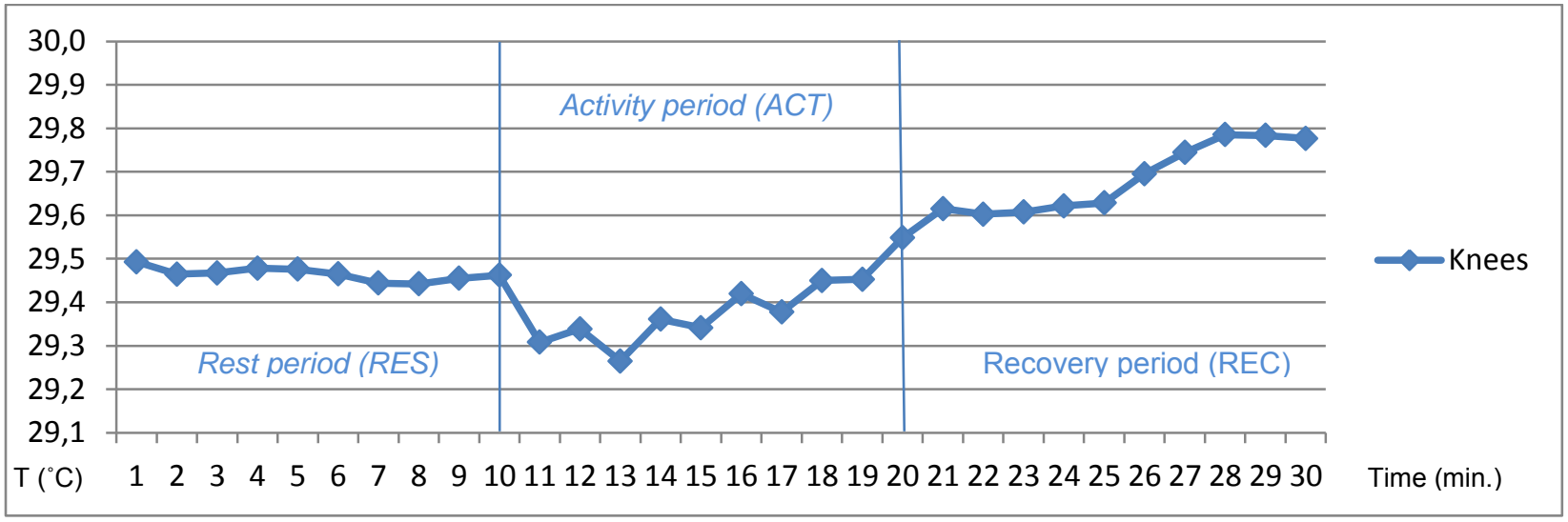

Fig. 1. Mean skin temperature $\left({ }^{\circ} \mathrm{C}\right)$ of the knees during 30 minutes of measuring

After the first minute $(\mathrm{t}=11 \mathrm{~min})$ of $\mathrm{ACT}$ there is a relative decrease of $-0.16{ }^{\circ} \mathrm{C}$ in the temperature compared to mean RES values, followed by a relative rise in skin temperature of $0.03{ }^{\circ} \mathrm{C}$ measured after the second minute $(t=12)$ of $A C T$. At point $t=13$ min the relative decrease of $T_{s k}$ was $-0.08{ }^{\circ} \mathrm{C}$ following a positive rise of $\mathrm{T}_{s k}$ of $0.10{ }^{\circ} \mathrm{C}$ at $\mathrm{t}=14 \mathrm{~min}$. There was yet another relative fall in $\mathrm{T}_{\mathrm{sk}}$ at $\mathrm{t}=15 \mathrm{~min}$ of $-0.02{ }^{\circ} \mathrm{C}$ followed by a rise in $\mathrm{T}_{\mathrm{sk}}$ of $0.08{ }^{\circ} \mathrm{C}(\mathrm{t}=16$ $\min )$ and $\mathrm{t}=17 \mathrm{~min}$ of $-0.04{ }^{\circ} \mathrm{C}$ followed by a rise of $0.07{ }^{\circ} \mathrm{C}(\mathrm{t}=18 \mathrm{~min})$. This negative $\mathrm{T}_{\text {sk }}$ change $(\Delta \mathrm{T})$ during interval work occurs until blood flow temperature together with the conduction of heath from the core reach the same or higher level of a positive $\mathrm{T}_{\text {sk }}$ change. This "changing point" can be seen after eight minutes ( $\mathrm{t}=18$ min) of activity of our investigation. At point $\mathrm{t}=19$ min warming up of the skin surround knee joints was high enough to cover a relative negative change resulting from the higher demand of the blood flow in working musculature. Therefore difference in $T_{\text {sk }}$ between two measuring points $\left(T_{t 19 \min -118 \min }=0.00\right)$ does not exist. For these reasons and the complexity of the human body IRT still has a lot of challenges and the analysis of the skin temperature has to be made cautiously. After $t=19$ min a gradual rise in $T_{s k}$ is seen. This warming of the skin continues during REC until the peak temperature of $29.8^{\circ} \mathrm{C}$ was reached after eight minutes $(\mathrm{t}=28 \mathrm{~min}$ ) of recovery. The difference between resting temperature and peak temperature during recovery period was $0.33^{\circ} \mathrm{C}$. Results of "minute to minute" temperature analysis can be seen in table 2. 
Table 2. Mean skin temperature $\left({ }^{\circ} \mathrm{C}\right)$ of the knees over time (1-30 min.)

\begin{tabular}{|c|c|c|c|c|c|c|c|}
\hline \multirow[t]{2}{*}{ Time (min.) } & \multirow{2}{*}{$\frac{N}{\text { Statistic }}$} & \multirow{2}{*}{$\begin{array}{l}\text { Range } \\
\text { Statistic }\end{array}$} & \multirow{2}{*}{$\begin{array}{c}\text { Minimum } \\
\text { Statistic } \\
\end{array}$} & \multirow{2}{*}{$\begin{array}{c}\text { Maximum } \\
\text { Statistic }\end{array}$} & \multicolumn{2}{|c|}{ Mean } & \multirow{2}{*}{$\frac{S D}{\text { Statistic }}$} \\
\hline & & & & & Statistic & Std. Error & \\
\hline t1 & 23 & 2.3 & 28.3 & 30.5 & 29.49 & 0.13 & 0.64 \\
\hline t2 & 23 & 2.2 & 28.2 & 30.4 & 29.46 & 0.13 & 0.62 \\
\hline t3 & 23 & 2.2 & 28.2 & 30.4 & 29.47 & 0.14 & 0.65 \\
\hline t4 & 23 & 2.2 & 28.3 & 30.4 & 29.48 & 0.13 & 0.62 \\
\hline t5 & 23 & 2.2 & 28.3 & 30.5 & 29.48 & 0.13 & 0.64 \\
\hline t6 & 23 & 2.2 & 28.3 & 30.4 & 29.47 & 0.13 & 0.62 \\
\hline t7 & 23 & 2.1 & 28.3 & 30.4 & 29.44 & 0.13 & 0.62 \\
\hline t8 & 23 & 2.1 & 28.3 & 30.4 & 29.44 & 0.13 & 0.61 \\
\hline t9 & 23 & 2.2 & 28.2 & 30.4 & 29.46 & 0.13 & 0.62 \\
\hline t10 & 23 & 2.2 & 28.2 & 30.4 & 29.46 & 0.13 & 0.61 \\
\hline t11 & 23 & 2.0 & 28.1 & 30.1 & 29.31 & 0.12 & 0.60 \\
\hline $\mathrm{t} 12$ & 23 & 2.2 & 28.0 & 30.2 & 29.34 & 0.13 & 0.62 \\
\hline t13 & 23 & 2.1 & 27.9 & 30.0 & 29.26 & 0.13 & 0.61 \\
\hline $\mathrm{t} 14$ & 23 & 2.3 & 28.0 & 30.3 & 29.36 & 0.13 & 0.62 \\
\hline t15 & 23 & 2.7 & 28.0 & 30.7 & 29.34 & 0.14 & 0.65 \\
\hline t16 & 23 & 2.4 & 28.1 & 30.5 & 29.42 & 0.13 & 0.61 \\
\hline t17 & 23 & 2.7 & 28.1 & 30.8 & 29.38 & 0.13 & 0.62 \\
\hline t18 & 23 & 2.6 & 28.1 & 30.7 & 29.45 & 0.13 & 0.62 \\
\hline t19 & 23 & 2.7 & 28.2 & 30.8 & 29.45 & 0.13 & 0.62 \\
\hline t20 & 23 & 2.5 & 28.1 & 30.6 & 29.55 & 0.12 & 0.60 \\
\hline t21 & 23 & 2.5 & 28.1 & 30.6 & 29.62 & 0.13 & 0.60 \\
\hline t22 & 23 & 2.4 & 28.1 & 30.5 & 29.60 & 0.13 & 0.60 \\
\hline t23 & 23 & 2.5 & 28.1 & 30.6 & 29.61 & 0.13 & 0.60 \\
\hline t24 & 23 & 2.5 & 28.2 & 30.6 & 29.62 & 0.13 & 0.61 \\
\hline t25 & 23 & 2.4 & 28.2 & 30.6 & 29.63 & 0.13 & 0.61 \\
\hline t26 & 23 & 2.4 & 28.3 & 30.7 & 29.70 & 0.13 & 0.61 \\
\hline t27 & 23 & 2.5 & 28.3 & 30.7 & 29.74 & 0.13 & 0.62 \\
\hline t28 & 23 & 2.6 & 28.3 & 30.8 & 29.79 & 0.13 & 0.63 \\
\hline t29 & 23 & 2.7 & 28.3 & 31.0 & 29.78 & 0.13 & 0.64 \\
\hline t30 & 23 & 2.5 & 28.4 & 30.9 & 29.78 & 0.13 & 0.64 \\
\hline
\end{tabular}

${ }^{*} \mathrm{~N}$ - number of participants SD - standard deviation

Testing of normality of the data using skewness and kurtosis values and analysing histograms and Q-Q plots showed that knee temperatures were normaly distributed which made it possible to proceed with quantitative analysis. The level of significance was set to $p<0.05$. Three separate t-tests for paired samples were used to determine differences between mean temperatures of the knees during rest, activity and recovery periods (table 3 ). Statistically significant differences were found between mean activity and mean recovery periods $T_{\text {sk }}(t=-6.142 ; p=0.000)$ and 


\subsection{1/qirt.2016.130}

mean rest and mean recovery $T_{s k}(t=-2.711 ; p=0.013)$. The mean resting temperature was $0.22{ }^{\circ} \mathrm{C}$ lower then mean recovery temperature, and mead activity temperature was $0.30{ }^{\circ} \mathrm{C}$ lover then mean recovery temperature of the skin. Statistical difference was not found between mean rest and mean activity $T_{\text {sk }}(t=1.443 ; p=0.163)$ which was expected because of 30 seconds short periods of rest that influenced mean activity temperature. It can be hypothesized that the difference between rest and recovery temperature is highly correlated with the total physical work done during the activity phase and energy expenditure. The information of the temperature drop at the beginning of the exercise (especially during first couple of minutes) could show us the intensity of the activity.

Table 3. Results of t-tests for mean temperature values

\begin{tabular}{|c|c|c|c|c|c|}
\hline & Mean & $S D$ & $d f$ & $t$ & $P$ \\
\hline Pair 1 Tres $-T_{\text {act }}$ & 0.079 & 0.261 & 22 & 1.443 & 0.163 \\
\hline Pair 2 $T_{\text {res }}-T_{\text {rec }}$ & -0.221 & 0.391 & 22 & -2.711 & 0.013 \\
\hline Pair 3 $T_{\text {act }}-T_{\text {rec }}$ & -0.300 & 0.234 & 22 & -6.142 & 0.000 \\
\hline
\end{tabular}

${ }^{*} T_{\text {res }}-$ mean rest temp., $T_{\text {act }}-$ mean activity temp., $T_{\text {rec }}-$ mean recovery temp., SD - standard deviation, df - degrees of freedom, $\mathrm{t}$ - test value, $\mathrm{p}$ - value

Difference between left and right knee temperatures during all three periods we also analysed in this study. The results put in graph (Fig.2.) show us clearly the difference in skin temperature during the activity period between right and left knees. The dominant side of the body is something sport is very susceptible to. From unilateral to bilateral sports, simple or complex movement, acyclic or cyclic activities there is always a small difference in engaging the left and right side of the body.

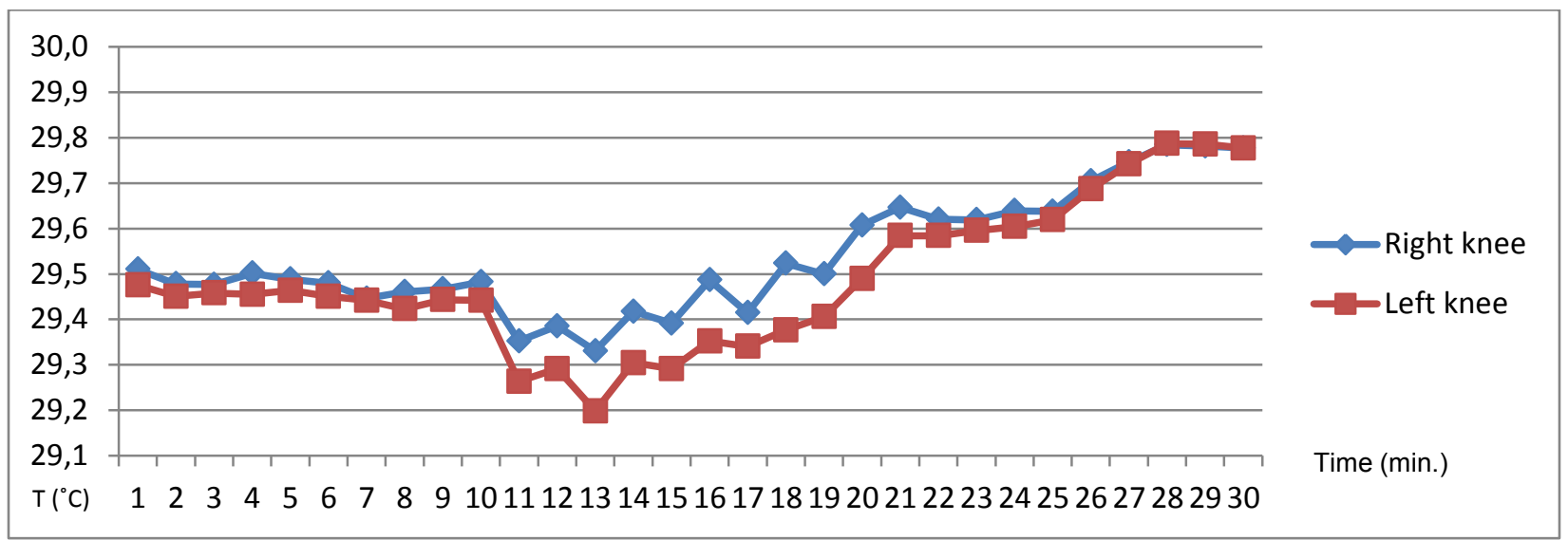

Fig. 2. Mean skin temperatures $\left({ }^{\circ} \mathrm{C}\right)$ of left and right knee separately during 30 minutes of measuring

To test these differences during the activity period we used additional t-test for paired samples (table 4). Statistically significant difference was found between mean right and left knee temperatures of our subjects $(t=2.313 ; p=0.030)$. Our results show that mean temperature of the right knees was $0.10{ }^{\circ} \mathrm{C}$ higher then mean of the left knees during the ACT. The most probable reason for these differences is the left leg being dominant in the population which means that during physical activity the left leg is the one being used just a "little more" then the right leg. These results give us a slightly new view of our standing point on how we analyse thermograms during physical activities. Although asymmetries [8] could show us certain pathology in the regions of interest, this is not such a case. 
10.21611/qirt.2016.130

Table 4. Results of t-test for mean temperature values of right and left knees during activity period

\begin{tabular}{|l|c|c|c|c|c|c|c|c|}
\hline & $N$ & Range & Minimum & Maximum & Mean & SD & Skewness & Kurtosis \\
\hline Right knee & 23 & 2.4 & 28.0 & 30.4 & 29.44 & 0.64 & -0.71 & -0.21 \\
\hline Left knee & 23 & 2.3 & 28.2 & 30.5 & 29.33 & 0.56 & -0.29 & 0.11 \\
\hline
\end{tabular}

\begin{tabular}{|c|c|c|c|c|c|}
\hline T-test & Mean & SD & df & t & p \\
\hline Pair 1 Right knee-Left knee & 0.104 & 0.216 & 22 & 2.313 & 0.030 \\
\hline
\end{tabular}

${ }^{*} \mathrm{SD}$ - standard deviation

\section{Conclusion}

Similar to the changes of skin temperature during continuous work [9], the interval work affects a fall in skin temperature at the beginning of the exercise as a response to the vasoconstriction skin reflex. This level of negative $\mathrm{T}_{\text {sk }}$ change is relative to the time spent in the physical activity by warming up the body. These findings suggest that the intensity and the type of physical exercise highly influence the dynamic of thermoregulation and skin temperature over the active musculature and joints. More work is still needed in order to functionally correlate level of intensity with the level of skin temperature fall at the beginning of activity. Heart rate monitoring and IRT can give us useful non-invasive information of physiological activity of an athlete body, especially when taken into consideration latest studies which show: 1. that anaerobic effort is accompanied by a substantial drop of the temperature on surface of engaged muscles and the degree of the drop is proportional to the blood lactate concentration [10], and 2. the use of skin temperature as a physiological indicator of energy expenditure [11]. Baseline images of the rest period combined with images during sport-specific exercise provoke certain patterns that can help us better understand regulation of skin blood flow and thermoregulation of athletes and can be a helpful tool in sport, sports medicine and physical therapy. Lateral differences of the body need to be taken into consideration whenever comparing thermograms during the activity in order to get the exact results.

\section{REFERENCES}

[1] Costello, J., Stewart, I.B., Selfe, J., Kärki, A.I. \& Donnelly A.E., "Use of thermal imaging in sports medicine research: A short report". International SportMed Journal, vol. 14(2), pp. 94-98, 2013.

[2] Merla, A., Mattei, P.A., Di Donato, L. \& Romani, G.L., "Thermal imaging of cutaneous temperature modifications in runners during graded exercise". Annals of biomedical engineering, vol. 38(1), p.p. 158-163, 2010.

[3] Zontak, A., Sideman, S., Verbitsky, O. \& Beyar, R., "Dynamic thermography: analysis of hand temperature during exercise. Annals of Biomedical Engineering, vol. 26(6), p.p. 988-993, 1998.

[4] Sampedro, J., Piñonosa, S. \& Fernandez, I. Thermography as a new assessment tool in basketball. Pilot study carried out with a professional player in the ACB. Cuadernos de Psicología del Deporte, vol. 12 (1), pp. 51-56, 2012.

[5] Novotny, J., Rybarova, S., Zacha, D., Bernacikova, M. \& Ramadan, W.A. The influence of breaststroke swimming on the muscle activity of young men in thermographic imaging. Acta of Bioengineering and Biomechanics, vol. 17(2), pp. 121-129, 2015.

[6] Piñonosa, S., Sillero-Quintana, M., Milanović, L., Coterón, J. \& Sampedro, J. Thermal evolution of lower limbs during a rehabilitation process after anterior cruciate ligament surgery. Kinesiology, vol. 45(1), pp. 121-129, 2013.

[7] Ammer, K., "The Glamorgan Protocol for recording and evaluation of thermal images of the human body". Thermology international, vol. 18, p.p. 125-144, 2008.

[8] Vardasca, R. Symmetry of temperature distribution in the upper and lower extremities. Thermology International, 18, 154-155, 2008.

[9] Švaić, V., Jurinjak, B., Županić, D. \& Bolarić, A. "Dynamics of skin temperature of the knee during physical exercise measured by infrared thermography", Proceedings of $12^{\text {th }}$ Quantitative Infrared Thermography Conference, paper QIRT2014-131, Bordeaux, France. 


\subsection{1/qirt.2016.130}

[10] Adamczyk, J.G., Boguszewski, D. \& Siewierski, M. Thermographic evaluation of lactate level in capillary blood during post-exercise recovery. Kinesiology, 46(2), pp. 186-193, 2014.

[11] Seixas, A., Gonjo, T., Vardasca, R., Gabriel, J., Fernandes, R. \& Vilas-Boas, J.P. "A preliminary study on the relationship between energy expenditure and skin temperature in swimming", Proceedings of $12^{\text {th }}$ Quantitative Infrared Thermography Conference, paper QIRT2014-097, Bordeaux, France. 